\title{
Activity of rifampicin and linezolid combination in Mycobacterium tuberculosis
}

\author{
Flaviane Granero Maltempe a, Katiany Rizzieri Caleffi-Ferracioli ${ }^{\mathrm{b}}$, \\ Renata Claro Ribeiro do Amaral ${ }^{a}$, Fernanda de Oliveira Demitto ${ }^{c}$, \\ Vera Lúcia Dias Siqueira ${ }^{b}$, Regiane Bertin de Lima Scodro ${ }^{b}$, Mário Hiroyuki Hirata ${ }^{\text {d }}$, \\ Fernando Rogério Pavan ${ }^{\mathrm{e}}$, Rosilene Fressatti Cardoso ${ }^{\mathrm{b}, *}$ \\ a Postgraduation in Bioscience and Physiopathology, State University of Maringá, Avenida Colombo 5790, Maringá, Paraná, 87020-900, Brazil \\ ${ }^{\mathrm{b}}$ Laboratory of Medical Bacteriology, Laboratory of Teaching and Research in Clinical Analysis (LEPAC), Department of Clinical Analysis and Biomedicine, \\ State University of Maringa, Avenida Colombo 5790, Maringá, Paraná, 87020-900, Brazil \\ ${ }^{c}$ Postgraduation in Health Sciences, State University of Maringá, Avenida Colombo 5790, Maringá, Paraná, 87020-900, Brazil \\ d School of Pharmaceutical Sciences, University of São Paulo, São Paulo, 05508-900, Brazil \\ e School of Pharmaceutical Sciences, Department of Biological Sciences, Paulista State University, Araraquara, São Paulo, 14800-901, Brazil
}

\section{A R T I C L E I N F O}

\section{Article history:}

Received 25 October 2016

Accepted 15 February 2017

\section{Keywords:}

Drug resistance

Treatment

Tuberculosis

Linezolid and rifampicin combination

\begin{abstract}
A B S T R A C T
Background: Linezolid (LZD) is not commonly used for treating tuberculosis (TB), but in some patients with drug-resistant TB it is being used. However, the in vitro LZD activity, in combination with rifampicin (RIF) against Mycobacterium tuberculosis has not been fully elucidated.

Aims: The aim of this study was to evaluate the in vitro activity of RIF/LZD combination against M. tuberculosis clinical isolates.

Materials and methods: The activity of the RIF/LZD combination was firstly determined in M. tuberculosis $\mathrm{H}_{37} \mathrm{Rv}, 14$ susceptible, 9 isoniazid nonresistant and 14 multi-drug resistant (MDR) M. tuberculosis clinical isolates by modified checkerboard assay, Resazurin Drugs Combination Microtiter Assay (REDCA). After, the Time Kill Curve Assay, at $0.5 \times$ MIC of drugs, in combination and alone, was performed in M. tuberculosis $\mathrm{H}_{37} \mathrm{Rv}$ and 8 (20.5\%) of those clinical isolates, which the RIF/LZD combination showed to have synergistic effect by the checkerboard assay.

Results and conclusion: By Time Kill Curve Assay, we could observe in M. tuberculosis $\mathrm{H}_{37} \mathrm{Rv}$ and susceptible isolates, that LZD alone, at sub inhibitory concentration, has poor effect on the bacillus death. In some cases, the bacillus growth stayed constant while in others showed regrowth at the eighth day of drug exposure. RIF alone exhibits potent concentration-dependent bactericidal activity, and was strongly dependent by the drug exposure time. The RIF/LZD combination accomplished a bacteriostatic effect in the reference strain and susceptible isolates. For the RIF resistant isolates, the RIF/LZD combination did not enhance the effect in killing bacillus. In this sense, additional, in vitro and in vivo studies are needed to evaluate the effect of RIF/LZD combination in order to better understand the adjunctive action of LZD in the treatment of TB and prevent the emergence of mutants with resistance to the available anti-TB drugs.
\end{abstract}

() 2017 Elsevier Ltd. All rights reserved.

\section{Introduction}

The emergence of drug-resistant tuberculosis (TB), especially multi-drug resistant TB (MDR-TB) and extensively drug-resistant

\footnotetext{
* Corresponding author.

E-mail address: rfressatticardoso@gmail.com (R.F. Cardoso).
}

TB (XDR-TB), has been a major concern for the control of TB epidemic worldwide [1].

At present, the number of available drugs for treatment of drugresistant TB is limited and requires the use of second-line drugs, which are more expensive, less effective, more toxic, and require prolonged time of treatment. As the discovery of new therapeutic agents has had few effective proposals, some drugs, already available for the treatment of infectious diseases caused by other 
bacterial species, are being redirected to the treatment of drugresistant TB. In this sense, clinical studies on using linezolid, rifapentine, moxifloxacin, gatifloxacin and others are undergoing [2,3].

Linezolid (LZD), a drug pertaining to the oxazolidinone class, was approved by the Food and Drug Administration (FDA) in 2000 for the treatment of skin and soft tissue infection, pneumonia and other infections caused by Gram-positive bacteria that are resistant to several drugs, which include vancomycin-resistant enterococci [4].

LZD showed to be highly active, in vivo [5] and in vitro [6], against Mycobacterium tuberculosis, and in some rapidly [7,8] and slowly [9] growing non-tuberculous mycobacteria. Although, LZD is not commonly used for treatment of $\mathrm{TB}$, it has been used as an alternative for treating patients with drug-resistant $\mathrm{TB}$ to most commonly used anti-TB drugs [10]. However, the in vitro activity of LZD alone or in combination with other drugs against M. tuberculosis has not been fully elucidated yet [11].

Considering the promising results obtained in clinical practice by using LZD in treatment of patients with highly drug-resistant TB, which may be an important therapeutic option, the aim of our study was to evaluate the in vitro activity of RIF/LZD combination against $M$. tuberculosis clinical isolates by a modified checkerboard method, the Resazurin Drugs Combination Microtiter Assay (REDCA) and Time Kill Curve Assay. The selection of RIF for the study was based on its potent bactericidal effect, which plays a special role in the reduction of drug-resistant TB treatment time. In addition, the resistance to RIF submits the patient to a longer treatment with more toxic drugs. The study was conducted in two steps: Firstly, the REDCA was carried out to investigate RIF/LZD synergism or antagonism. After, the Time Kill Curve Assay was carried out, in isolates where the RIF/LZD combination showed synergistic effect, to provide a dynamic picture of RIF/LZD combination action and interaction over time.

\section{Materials and methods}

\subsection{Bacterial samples}

M. tuberculosis $\mathrm{H}_{37} \mathrm{Rv}$ (ATCC 27294), and 37 M. tuberculosis clinical isolates (14 susceptible, 9 isoniazid (INH)-monoresistant and 14 MDR, previously tested for susceptibility, by the proportion method on Lowenstein-Jensen medium [12] and genotyped by Mycobacterial Interspersed Repetitive Units (MIRU) [13] and Spoligotyping [14] were studied. The reference strain and clinical isolates were firstly grown in Middlebrook 7H9 medium (Difco Laboratories, Detroit, MI, USA) supplemented with oleic acid, bovine serum albumin, dextrose and catalase (OADC) enrichment (BBL/Becton-Dickinson, Sparks, MD, USA) added with $0.2 \%$ glycerol $(\mathrm{v} / \mathrm{v})$ and $0.025 \%$ tween $80(\mathrm{v} / \mathrm{v})$ for 15 days at $35-37^{\circ} \mathrm{C}$.

Table 1

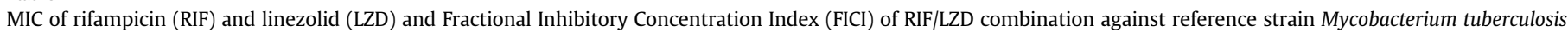
$\mathrm{H}_{37} \mathrm{R}_{\mathrm{V}}$ and clinical isolates.

\begin{tabular}{|c|c|c|c|c|c|c|}
\hline \multirow[t]{2}{*}{ Isolates } & \multirow[t]{2}{*}{ Spoligotyping } & \multirow[t]{2}{*}{ MIRU } & \multirow[t]{2}{*}{ Susceptibility profile $^{a}$} & \multicolumn{2}{|c|}{$\mathrm{MIC}(\mu \mathrm{g} / \mathrm{ml})$} & \multirow{2}{*}{$\begin{array}{l}\text { FICI } \\
\text { RIF/LZD }\end{array}$} \\
\hline & & & & RIF & LZD & \\
\hline H37Rv & NP & NP & Susceptible & 0.125 & 0.5 & 0.250 \\
\hline 14 & 777777777760771 & 324125153321 & Susceptible & 0.004 & 0.5 & 0.750 \\
\hline 20 & 777777607760771 & 224221143223 & Susceptible & 0.03 & 0.125 & 1.500 \\
\hline 23 & 377777607760771 & 123226143321 & Susceptible & 0.125 & 0.125 & 0.98 \\
\hline 25 & 377777607760771 & 224226143321 & Susceptible & 0.06 & 0.25 & 2 \\
\hline 46 & 777777774020771 & 224326132323 & Susceptible & 0.03 & 0.5 & 0.370 \\
\hline 50 & 777777607560771 & 124326132222 & Susceptible & 0.004 & 0.5 & 2 \\
\hline 51 & 777777607760731 & 124326132324 & Susceptible & 0.125 & 0.25 & 2 \\
\hline 57 & 577777607760771 & 123326132321 & Susceptible & 0.03 & 0.25 & 2 \\
\hline 60 & 377777607760771 & 224236152321 & Susceptible & 0.125 & 0.25 & 0.750 \\
\hline 65 & 777777607760731 & 125336543324 & Susceptible & 0.06 & 0.125 & 1.020 \\
\hline $69 A$ & 777777777720771 & $\mathrm{NP}$ & Susceptible & 0.125 & 0.5 & 0.306 \\
\hline 97 & 777777777760731 & 124306143324 & Susceptible & 0.06 & 0.25 & 2 \\
\hline 25252 & 000000007760771 & NP & Susceptible & 0.25 & 0.25 & 1 \\
\hline 3 & NP & 124326163324 & INH & 0.004 & 0.5 & 2 \\
\hline 12 & NP & 324326143324 & INH & 0.03 & 0.125 & 2 \\
\hline 34 & NP & 122222153321 & INH & 0.008 & 0.125 & 1.500 \\
\hline 43 & NP & 124326143324 & INH & 0.125 & 0.5 & 0.047 \\
\hline 48 & NP & 223326132424 & INH & 0.06 & 0.25 & 0.760 \\
\hline 52 & NP & 224313132324 & INH & 0.06 & 0.125 & 1.020 \\
\hline 91 & 677737607760771 & $\mathrm{NP}$ & INH & 0.06 & 0.5 & 0.760 \\
\hline 1193 & 777777777720771 & NP & INH & 0.06 & 0.25 & 0.760 \\
\hline 4250 & 777777777760710 & $\mathrm{NP}$ & INH & 0.125 & 0.50 & 0.258 \\
\hline 18 & 776177607760771 & 224326153324 & INH/RIF/EMB & 125 & 0.5 & 0.375 \\
\hline 19 & 776177607760771 & 224327153324 & INH/RIF/EMB & 31.25 & 0.5 & 1 \\
\hline $40 \mathrm{~A}$ & 777777607760771 & $\mathrm{NP}$ & INH/RIF & 250 & 0.5 & 1 \\
\hline $64 \mathrm{~A}$ & 677737607760771 & 124325163322 & INH/RIF & 125 & 0.125 & 1 \\
\hline $68 \mathrm{~A}$ & 776177607760771 & NP & INH/RIF/PZA & 62.5 & 0.25 & 0.750 \\
\hline $71 \mathrm{~A}$ & 777777777720771 & 225313153323 & INH/RIF/PZA & 12 & 0.25 & 0.625 \\
\hline $73 \mathrm{~A}$ & 677737607760771 & 224225123321 & INH/RIF/PZA & 4 & 0.125 & 0.750 \\
\hline 109 & 776177607760771 & 224326153325 & INH/RIF & $62 \cdot 5$ & 0.5 & 1 \\
\hline 3408 & 000000000003771 & NP & INH/RIF/EMB/STR & 64 & 0.125 & 1.500 \\
\hline 3614 & 677737607760771 & 224225163321 & INH/RIF/EMB/STR/ETH & 8 & 0.125 & 1 \\
\hline 485 & 677737607600771 & NP & INH/RIF/STR & 62.5 & 0.25 & 1 \\
\hline 309 & 776177607760771 & NP & INH/RIF/STR & 250 & 0.25 & 0.312 \\
\hline 251-S & 377777607760771 & NP & INH/RIF & 8 & 0.5 & 0.749 \\
\hline $97-S$ & 777777607560771 & NP & INH/RIF/STR & 8 & 2.5 & 0.313 \\
\hline
\end{tabular}

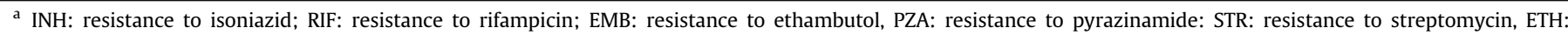
resistance to ethionamide, Numbers in bold are synergism, NP: Not performed. 


\subsection{Minimal inhibitory concentration (MIC)}

The MICs of LZD (Zyvox ${ }^{\circledR}$, Pfizer, Brazil) and RIF (Sigma, St Louis, USA) for M. tuberculosis $\mathrm{H}_{37} \mathrm{Rv}$ and the clinical isolates were performed three times on different days by Resazurin Microtiter Plate Assay (REMA) as described by Palomino et al. [15]. Bacterial growth and sterility controls were performed in all assays. The MIC was assessed visually by color change from blue to pink, which indicates reduction of resazurin by bacterial growth.

\subsection{Resazurin Drugs Combination Microtiter Assay - REDCA}

The antimicrobial activity of RIF/LZD combination was performed three times on different days by REDCA [16] in microtiter plates with 96 wells. The fractional inhibitory concentration index (FICI) was used to evaluate the combination effect, and the results were interpreted as synergism (FICI $\leq 0.5$ ), no interaction (IFI > 0.5-4) and antagonism (FICI > 4) [17].

\subsection{Time Kill study}

The Time Kill Curve Assay was performed three times on different days as described by Limoncu et al. [18], with modifications for drug combinations in M. tuberculosis $\mathrm{H}_{37} \mathrm{Rv}$ and clinical isolates, which previously showed synergistic effect by REDCA (46, 69A, 43, 4250, 18, 309, 97-S). LZD, RIF and RIF/LZD drug combination were added to each standardized mycobacterial suspension to achieve $0.5 \times$ MIC of drugs previously determined for each isolate. A growth control containing no drug was also included. The cultures were incubated at $35-37{ }^{\circ} \mathrm{C}$ under shaking at $96 \mathrm{rpm}$ for 8 days. Aliquots $(100 \mu \mathrm{l})$ of each mycobacterial growth at initial, 3, 5 and 8 days, were serially diluted in phosphate buffered saline (PBS) to $10^{-1}, 10^{-3}$ and $10^{-5}$ and plated on Middlebrook 7H11 agar (Difco Laboratories, Detroit, MI, USA) supplemented with OADC. All plates were incubated at $35-37^{\circ} \mathrm{C}$ for 21 days at normal atmosphere and after the colony forming units (CFUs) counting was carried out.

\section{Results}

The MIC of RIF for susceptible (including INH monoresistant isolates) and RIF resistant $M$. tuberculosis clinical isolates ranged from 0.004 to $0.25 \mu \mathrm{g} / \mathrm{ml}$ and $4-250 \mu \mathrm{g} / \mathrm{ml}$, respectively. For LZD, the MIC ranged from 0.125 to $0.5 \mu \mathrm{g} / \mathrm{ml}$ for susceptible and $0.125-2.5 \mu \mathrm{g} / \mathrm{ml}$ for RIF resistant clinical isolates (Table 1).

By REDCA, the synergistic effect of RIF/LZD combination $(\mathrm{FICI} \leq 0.5)$ was observed in $M$. tuberculosis $\mathrm{H}_{37} \mathrm{Rv}$ and $8(20.5 \%)$ clinical isolates. From these, 3 (37.5\%) isolates were susceptible, 2 (25.0\%) INH monoresistant and 3 (37.5\%) MDR. No antagonism with the drugs combination tested (FICI $>4$ ) was observed (Table 1 ).

The Time Kill curve assay for the $\mathrm{H}_{37} \mathrm{Rv}, 4 \mathrm{RIF}$ susceptible $(46,43$, 4250 and 69A) and 3 RIF resistant (18, 309 and 97-S) isolates are shown in Fig. 1. For the RIF susceptible isolates the RIF alone led to a reduction of bacterial concentration, starting at the third day, with $0.5 \times$ MIC concentration. No significant reduction of bacterial concentration was observed in RIF resistant isolates. The LZD alone showed reduction of bacilli concentration, in both susceptible and resistant isolates. However, that reduction was lower than the obtained with RIF alone. The RIF/LZD combination showed similar action to the one of RIF alone in susceptible and resistant isolate.

\section{Discussion}

It is understandable that a multidrug therapy is essential for the treatment of $\mathrm{TB}$, and is a way to avoid the emergence of resistant strains. Until new anti-TB drugs are developed to combat the drug- resistant $\mathrm{TB}$, novel combinations with the existing drugs are perhaps the best recourse in such scenario. Due to the varied resistant genotypes that may be exhibited by $M$. tuberculosis isolates, the selection of empirical drugs combination treatment is difficult because of the lack of common effective drugs combination for all resistant isolates.

Each new drug candidate or inclusion of a drug already used against other microorganism to be included for anti-TB therapy, needs to be assessed on its interactions with the classical anti-TB drugs currently used. This is essential in order to visualize the potential of interaction among the drugs and avoid possible antagonisms and then result in selection of resistant mutant bacilli.

To our knowledge, there was no extensive study on the use of LZD for treatment of MDR-TB or XDR-TB and, also, studies that evaluated the in vitro activity of LZD individually or in combination with anti-TB drugs in M. tuberculosis clinical isolates. Based on this, our study was conducted specifically to have a first insight about the in vitro activity of LZD and RIF alone and in combination against local susceptible and with decreased susceptibility to RIF M. tuberculosis clinical isolates.

The MIC values of LZD alone for $M$. tuberculosis, observed in this study $(0.125-2.5 \mu \mathrm{g} / \mathrm{ml})$, were similar to those observed in studies carried out by Guna et al. [8] $(0.125-4.0 \mu \mathrm{g} / \mathrm{ml})$, Ermertcan et al. [19] $(0.6-1.0 \mu \mathrm{g} / \mathrm{ml})$, Alffenaar et al. [20] $(\leq 0.25-1.0 \mu \mathrm{g} / \mathrm{ml})$, Alcala et al. [6] $(1.0-2.0 \mu \mathrm{g} / \mathrm{ml})$ and Yang et al. [21] $(0.125-0.5 \mu \mathrm{g} / \mathrm{ml})$, which included MDR and extensively-drug resistant (XDR) M. tuberculosis isolates in their works.

Although Rodriguez Díaz et al. [22] and Coban et al. [23] found no in vitro synergism with RIF/LZD combination, by classic checkerboard method, in RIF-monoresistant and MDR M. tuberculosis isolates, in our study, by a modified checkerboard method, REDCA, which uses resazurin for reading the assay, synergism was observed in $8 / 39(20.5 \%)$ of local clinical isolate. From these, $2 / 8(25 \%)$ were INH-monoresistant, 3/8 (37.5\%) were MDR and 3/8 (37.5\%) were susceptible isolates. In relation to the RIF susceptible clinical isolates, which account for 5/8 (62.5\%), our results are higher than those obtained by Rodriguez-Díaz et al. [22] that observed RIF/LZD synergism in $33 \%$ of RIF susceptible isolates.

Time Kill Curve Assays were carried out at sub inhibitory concentration $(0.5 \times \mathrm{MIC})$, previously determined for each drug individually and in combination in all isolates, in which synergism was previously observed by REDCA. The $0.5 \times$ MIC fixed concentration was chosen to compare the in vitro killing dynamics of RIF and LZD alone and in combination by the exposition time used in the REDCA. The better action of RIF against the bacillus, among the exposition time here, was in the eighth day of exposure for RIF susceptible isolates. Our results corroborate with the literature that RIF exhibits potent activity dependent of exposure time too [24]. The RIF resistant isolates $(18,309$ and $97-S)$ showed reduction in the bacterial inoculum concentration $<3 \log _{10} \mathrm{CFU} / \mathrm{ml}$ when exposed to RIF alone, which was expected by the RIF resistant status of the isolates.

LZD alone, at $0.5 \times \mathrm{MIC}$, had very poor effect on the RIF susceptible and resistant bacilli death. In some cases, the mycobacterial growth, in the assay with LZD alone, stayed constant and other showed bacillary regrowth at the eighth day of drug exposure.

Working with RIF exposure at $0.5 \times$ MIC, we also could observe that $\mathrm{H}_{37} \mathrm{Rv}$ and the clinical isolates 46 , in which both showed MIC $0.003 \mu \mathrm{g} / \mathrm{ml}$ for RIF, had $\geq 3 \log _{10} \mathrm{CFU} / \mathrm{ml}$ decrease in the colony counting, compared to the initial inoculum concentration, at 8 days of RIF exposure. The isolates 69A, 43 and 4250 also showed decrease in the colony count, at 8 days of RIF exposure, but not $\geq 3$ $\log _{10} \mathrm{CFU} / \mathrm{ml}$ as compared to the initial inoculum concentration. This may be attributed to the relatively higher RIF MICs $(0.125 \mu \mathrm{g} /$ $\mathrm{ml}$ ) that these isolates harbored. 
46

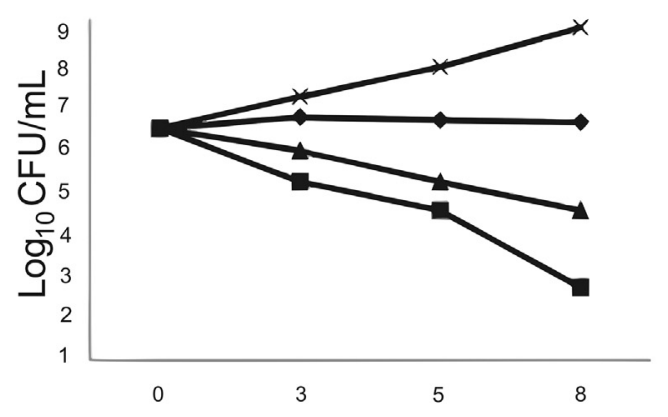

43

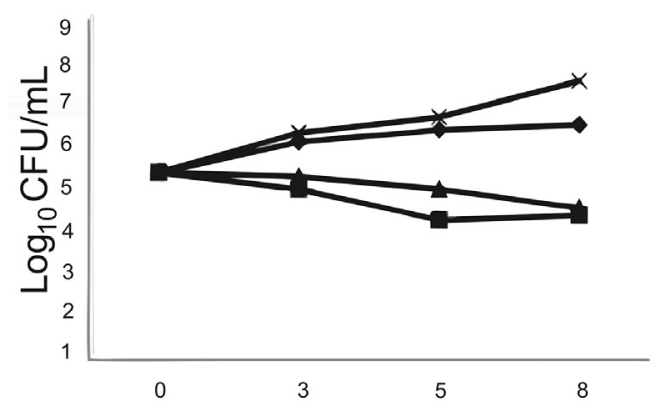

18

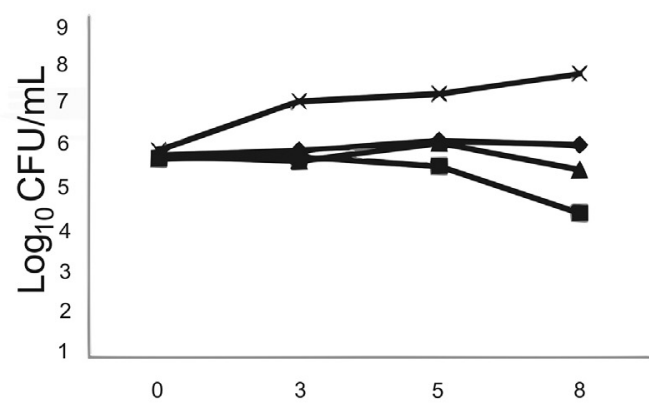

97-S

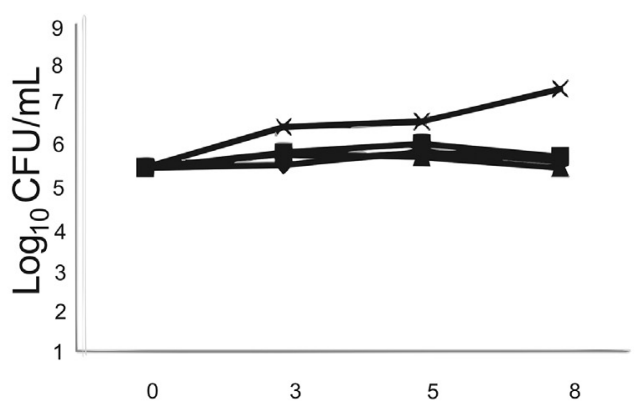

69A

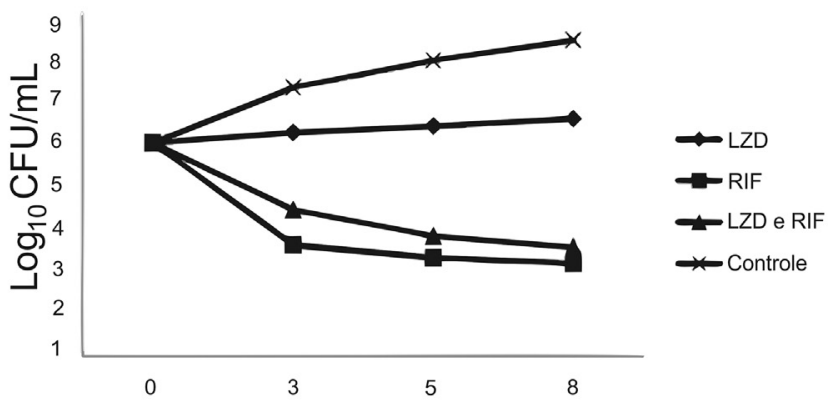

4250

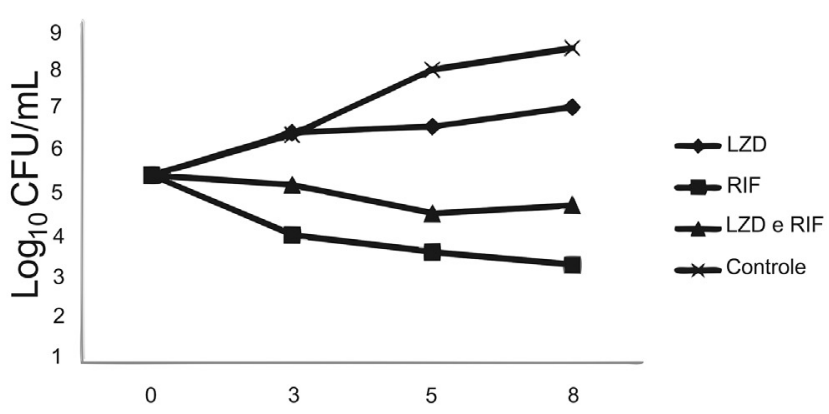

309

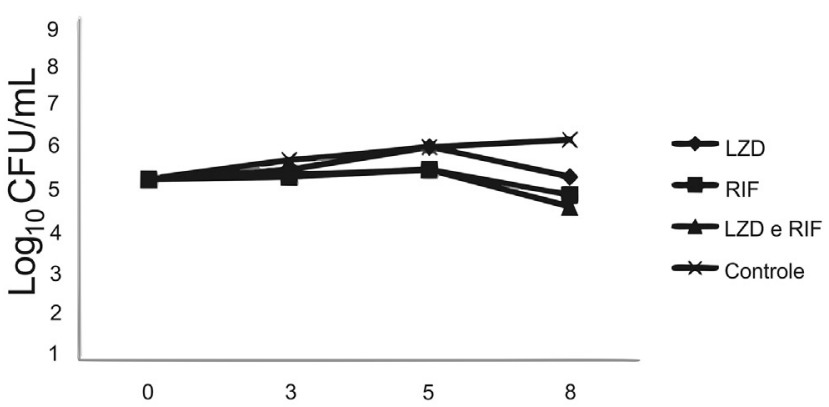

$\mathrm{H}_{37} \mathbf{R}$

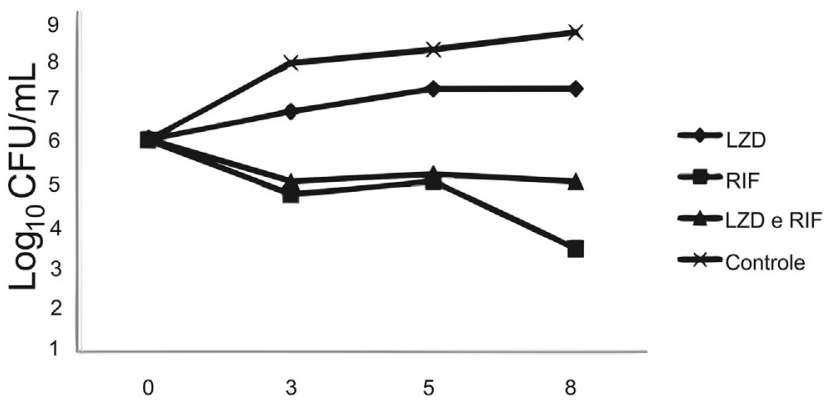

Fig. 1. Time Kill Curve of RIF susceptible $(46,43,69 \mathrm{~A}$ and 4250$)$, multidrug resistant $(18,309$ and $97-\mathrm{S})$ M. tuberculosis clinical isolates and the reference strain $\mathrm{H}_{37} \mathrm{R}_{\mathrm{V}}$.

The RIF/LZD combination, at $0.5 \times \mathrm{MIC}$, accomplished an in vitro bacteriostatic effect in the reference strain (decrease of $1 \log _{10} \mathrm{CFU} /$ $\mathrm{ml}$ ) and in the susceptible isolates (decrease of $\leq 1$ to 2.46 $\left.\log _{10} \mathrm{CFU} / \mathrm{ml}\right)$. For the RIF resistant isolates $(18,309,97-\mathrm{S})$ the RIF/ LZD combination did not enhanced the effect against the bacilli, as obtained with RIF alone. However, no antagonism was observed with the RIF/LZD combination in the studied local isolates.
In clinical practice, a LZD-containing regimen to treat some patients with XDR-TB has shown excellent results in combating this form of the disease [25-27]. In these specific cases, the drugs combination, including LZD, significantly improved patients clinical symptoms by closing pulmonary cavities, accelerate expectoration and caused sputum to be acid fast bacilli negative. However, it is hardly recommended that clinicians must monitor patients for 
several adverse reactions in using long-term LZD application. According to Lee et al. [27], to avoid this obstacle by the combined therapy, the dosage of $300 \mathrm{mg}$ per day of LZD is appropriate to maintain drug serum level and cause fewer adverse events.

In this analyzes we must consider the mechanism of action of the two studied drugs, RIF and LZD. The two drugs have actions by inhibiting the protein synthesis in the bacillus, although by different mechanisms. LZD inhibits protein synthesis by binding to the 23S ribosomal RNA, which is a component of ribosomal 50S subunit preventing the formation of ribosome (70S), which will impair the protein synthesis. RIF, also inhibits protein synthesis, but in a prior step, by binding to the beta subunit of the RNA polymerase (RpoB), encoded by rpo $\beta$ gene, that block the transcriptional process and consequently all the protein synthesis.

Then, depending on the causative mechanism of RIF resistance, as mutation in a defined region of the $r p o \beta$ gene or other unknown yet, the combined therapy with LZD could be very useful for some patients, as have been reported by some clinical studies [25-27]. However, attention to carefully use this combination should be clear due to the likelihood of developing LZD and RIF resistant mutants.

The research on drugs synergism or the detection of the lack of antagonism with RIF are of paramount importance, since RIF has a key role in reducing the time for treating TB [24]. We need to analyze each situation since it is well stated that RIF has considerable side effects, which often induce cessation of treatment by some patients and can lead to selection of resistant strains. The reduction of RIF and LZD dosage by the combination might be beneficial for some patients, as it reduces the undesirable effects and thereby improves treatment adherence. It is also interesting to note that the reduction of RIF dosages may be important in the treatment of HIV/AIDS co-infected patients, in which interaction with antiretroviral leads to RIF or antiretroviral decrease in serum [1]. On the other hand the increase of RIF dosage instead of using the combination should be taken into account in particular patients with low RIF resistance, in which the resistant mechanisms is not by $r p o B$, but by another mechanism as efflux pumps.

\section{Conclusion}

Finally, no antagonism between RIF and LZD was observed in our study with $M$. tuberculosis isolates. However, all should bear in mind that the study was carried out in vitro with a limited number of local clinical isolates and only with the combination of two drugs, RIF plus LZD. Additionally, the potential genetic differences among $M$. tuberculosis isolates in response to drugs must be considered.

In this sense, additional in vitro and in vivo studies are needed to evaluate the effect of RIF/LZD or combination with other anti-TB drugs such as INH and EMB, in order to better understand the adjunctive action of LZD in the treatment of TB. Nevertheless, in vivo studies will have also to be conducted in order to consider the combination of LZD and anti-TB drugs as an option to prevent the emergence of mutants with resistance to the available anti-TB drugs.

\section{Funding}

No funding.

\section{Ethical approval}

Not required.

\section{Competing interest}

The authors declare that they have no competing interest.

\section{Acknowledgements}

We are grateful to Laboratório de Bacteriologia Médica belonging to Laboratório de Ensino e Pesquisa em Análises Clínicas (LEPAC), Coordenação de Aperfeiçoamento de Pessoal de Nível Superior (CAPES) and Conselho Nacional de Desenvolvimento Científico e Tecnológico (CNPq), Brazil.

\section{References}

[1] WHO. World Health Organization. Global tuberculosis report 2014. Geneva: WHO Press; 2014.

[2] Ma Z, Lienhardt C, McIlleron H, Nunn AJ, Wang X. Global tuberculosis drug development pipeline: the need and the reality. Lancet 2010;375:2100-9.

[3] Millard J, Ugarte-Gil C, Moore DAJ. Multidrug resistant tuberculosis. Clin Rev BMJ 2015;350:h882.

[4] Zabransky RJ. Linezolid: the first of a new class of antimicrobial agents. Clin Microbiol News Lett 2012;24(4):25-30.

[5] Cynamom MH, Klemens SP, Sharpe CA, Chase S. Activities of several novel oxazolidinones against Mycobacterium tuberculosis in a murine model. Antimicrob Agents Chemother 1999;43(5):1189-91.

[6] Alcala L, Ruiz-Serrano MJ, Pérez-Fernández TC, García VD, Díaz-Infantes M, Marín-Arriaza M, et al. In vitro activities of linezolid against clinical isolates of Mycobacterium tuberculosis that are susceptible or resistant to first-line antituberculosous drugs. Antimicrob Agents Chemother 2003;47:416-7.

[7] Wallace RJ, Brown-Elliott BA, Ward SC, Crist CJ, Mann LB, Wilson RW. Activities of linezolid against rapidly growing mycobacteria. Antimicrob Agents Chemother 2001;43(3):764-7.

[8] Guna R, Muñoz C, Domínguez V, García-García A, Gálvez J, de Julián-Ortiz JV, et al. In vitro activity of linezolid, claritomycin and moxifloxacin against clinical isolates of mycobacterium kansassi. J Antimicrob Chemother 2005;55(6):950-3.

[9] Brown-Elliott BA, Crist CJ, Mann LB, Brown-Elliott BA, Crist CJ, Mann LB, et al. In vitro activity of linezolid againt slowly growing nontuberculous mycobacteria. Antimicrob Agents Chemother 2003;47(5):1736-8.

[10] Nam HS, Koh WJ, Kwon OJ, Cho SN, Shim TS. Daily half-dose linezolid for the treatment of intractable multidrug-resistant tuberculosis. Int J Antimicrob Agents 2009:33(1):92-3.

[11] Huang TS, Liu YC, Sy CL, Chen YS, Tu HZ, Chen BC. In vitro activities of linezolid against clinical isolates of Mycobacterium tuberculosis complex isolated in Taiwan over 10 years. Antimicrob Agents Chemother 2008;52(6):2226-7.

[12] Canetti G, Rist N, Grosset J. Mésure de la sensibilité du bacilli tuberculeux aux drogues antibacilares par la méthode des proportions. Rev Tuberc Pneumol 1963;27:217-72.

[13] Supply P, Allix C, Lesjean S, Cardoso-Oelemann M, Rüsch-Gerdes S, Willery E et al. Proposal for standardization of optimized mycobacterial interspersed repetitive unit-variable-number tandem repeat typing of Mycobacterium tuberculosis. J Clin Microbiol 2006;44:4498-510.

[14] Molhuizem HOF, Bunschoeten AE, Schouls LM, Van Embden JDA. Rapid detection and simultaneous strain differentiation of Mycobacterium tuberculosis complex bacteria by spoligotyping. Methods Mol Biol 1998;101:381-94.

[15] Palomino JC, Martin A, Camacho M, Guerra H, Swings J, Portaels F. Resazurin microtitre assay plate: simple and inexpensive method for detection of drug resistance in Mycobacterium tuberculosis. Antimicrob Agents Chemother 2002;46(8):2720-2.

[16] Caleffi-Ferracioli KR, Maltempe FG, Siqueira VL, Cardoso RF. Fast detection of drug interaction in Mycobacterium tuberculosis by a checkerboard resazurin method. Tuberculosis 2013;93(6):600-3.

[17] Pillai SK, Moellering RC, Eliopoulos GM. Antimicrobial combinations. In: Victor Lorian MD, editor. Antibiotics in laboratory medicine. Wilkins, Philadelphia USA: Lippincott Williams; 2003. p. 365-440.

[18] Limoncu MH, Ermertcan S, Erac B, Tașl H. An investigation of the antimicrobial impact of drug combinations against Mycobacterium tuberculosis strains. Turk J Med Sci 2011;41(4):719-24.

[19] Ermertcan S, Hosgor-Limoncu M, Erac B, Tasli H, Cavusoglu C, Bozkurt H. In vitro activity of linezolid against Mycobacterium tuberculosis strains isolate from western Turkey. Jpn J Infect Dis 2009;62(5):384-5.

[20] Alffenaar JW, Van der Laan T, Simons S, van der Werf TS, van de Kasteele PJ, de Neeling $\mathrm{H}$, et al. Susceptibility of clinical Mycobacterium tuberculosis isolates to a potentially less toxic derivate of linezolid, PNU-100480. Antimicrob Agents Chemother 2011;55(3):1287-9.

[21] Yang C, Lei H, Wang D, Meng X, He J, Tong A, et al. In vitro activity of linezolid against clinical isolates of Mycobacterium tuberculosis, including multidrugresistant and extensively drug-resistant strains from Beijing, China. Jpn J Infect Dis 2012;65(3):240-2.

[22] Rodriguez Díaz JC, Ruiz M, López M, Royo G. Synergic activity of 
fluoroquinolones and linezolid against Mycobacterium tuberculosis. Int J Antimicrob Agents 2003;21(4):354-6.

[23] Coban AY, Bilgin K, Uzun M. Effect of linezolid in combination with isoniazid and rifampicin against multidrug resistant Mycobacterium tuberculosis clinical isolates. Mikrobiyol Bul 2009;2(43):293-7.

[24] de Steenwinkel JE, de Knegt GJ, ten Kate MT, van Belkum A, Verbrugh HA Kremer K, et al. Time-kill kinetics of anti-tuberculosis drugs, and emergence of resistance, in relation to metabolic activity of Mycobacterium tuberculosis. J Antimicrob Chemother 2010;65(12):2582-9.
[25] Tangg SJ, Zhang Q, Zheng LH, Sun H, Gu J, Hao XH, et al. Efficacy and safety of linezolid in the treatment of extensively drug-resistant tuberculosis. Jpn J Infect Dis 2011;64(6):509-12.

[26] Lee M, Cho SN, Barry 3rd CE, Song T, Kim Y, Jeong I. Linezolid for XDR-TB-final study outcomes. N Engl J Med 2015;373(3):290-1.

[27] Lee M, Lee J, Carroll MW, Choi H, Min S, Song T, et al. Linezolid for treatment of chronic extensively drug-resistant tuberculosis. N Engl J Med 2012;367(16): 1508-18. 